TITLE:

\title{
A NEW SPECIES OF SPADELLA (CHAETOGNATHA) FROM CALIFORNIA
}

AUTHOR(S):

Bieri, Robert

\section{CITATION:}

Bieri, Robert. A NEW SPECIES OF SPADELLA (CHAETOGNATHA) FROM CALIFORNIA. PUBLICATIONS OF THE SETO MARINE BIOLOGICAL LABORATORY 1974, 21(3-4): 281-286

\section{ISSUE DATE:}

1974-03-30

URL:

http://hdl.handle.net/2433/175863

RIGHT: 


\title{
A NEW SPECIES OF SPADELLA (GHAETOGNATHA) FROM GALIFORNIA ${ }^{1)}$
}

\author{
RoBert BIERI \\ Antioch College, Yellow Springs, Ohio 45387
}

With Text-figures $1-4$

This species was first collected many years ago off San Diego when a small winch balked at the 1000 meters of wire J. S. Bradshaw and I put out. Before we could retrieve all the wire, the plankton net accidentally dragged on the bottom. As a result of our initial discovery we built a variety of bottom trawls using fine-meshed nets and were able to collect this new species of Spadella in good numbers along with an amazing number of other new and startling kinds of animals. A whole new frontier still awaits us in the study of the deeper meio-epibenthos of the Eastern Pacific-an almost completely unknown group of communities with not only their own unique meio-species, but also an abundance of larval forms from the macrofauna. Because of its striking appearance, this new species of Spadella helps to characterize the meio-epibenthos of the San Diego region.

\section{Spadella bradshawi, new species}

When freshly preserved in formalin the body is slender and stiff (Fig. 1a). The collarette extends around the head and along the trunk to the tail fin. It is easily damaged and in the type specimen it is difficult to trace beyond the transverse septum. However in other specimens it not only extends to the tail fin, but also covers the dorsal and ventral sides of the tail segment as well as the lateral fins. Where the collarette covers the lateral fins it has small papillate protuberances which appear as dots under low magnification. These are most abundant along the outer and anterior edges of the fins and are indicated in Fig. 2.

The corona ciliata is massive and rounded in freshly preserved specimens (Fig. 1a). The corona shrinks and becomes distorted with long preservation. Four different corona outlines are shown in Fig. 3. Figs. 3a and 3c were both drawn from the type specimen, $3 \mathrm{a}$ within twenty-four hours of preservation and $3 \mathrm{c}$ two months later. Fig. $3 \mathrm{~b}$ is the broken corona of the paratype and $3 \mathrm{~d}$ is the corona of a specimen preserved in dilute formalin nearly twenty years. Yosii and Tokioka

1) Contributions from the Seto Marine Biological Laboratory, No. 588.

Publ. Seto Mar. Biol. Lab., XXI (3/4), 281-286, 1974.

(Article 19) 

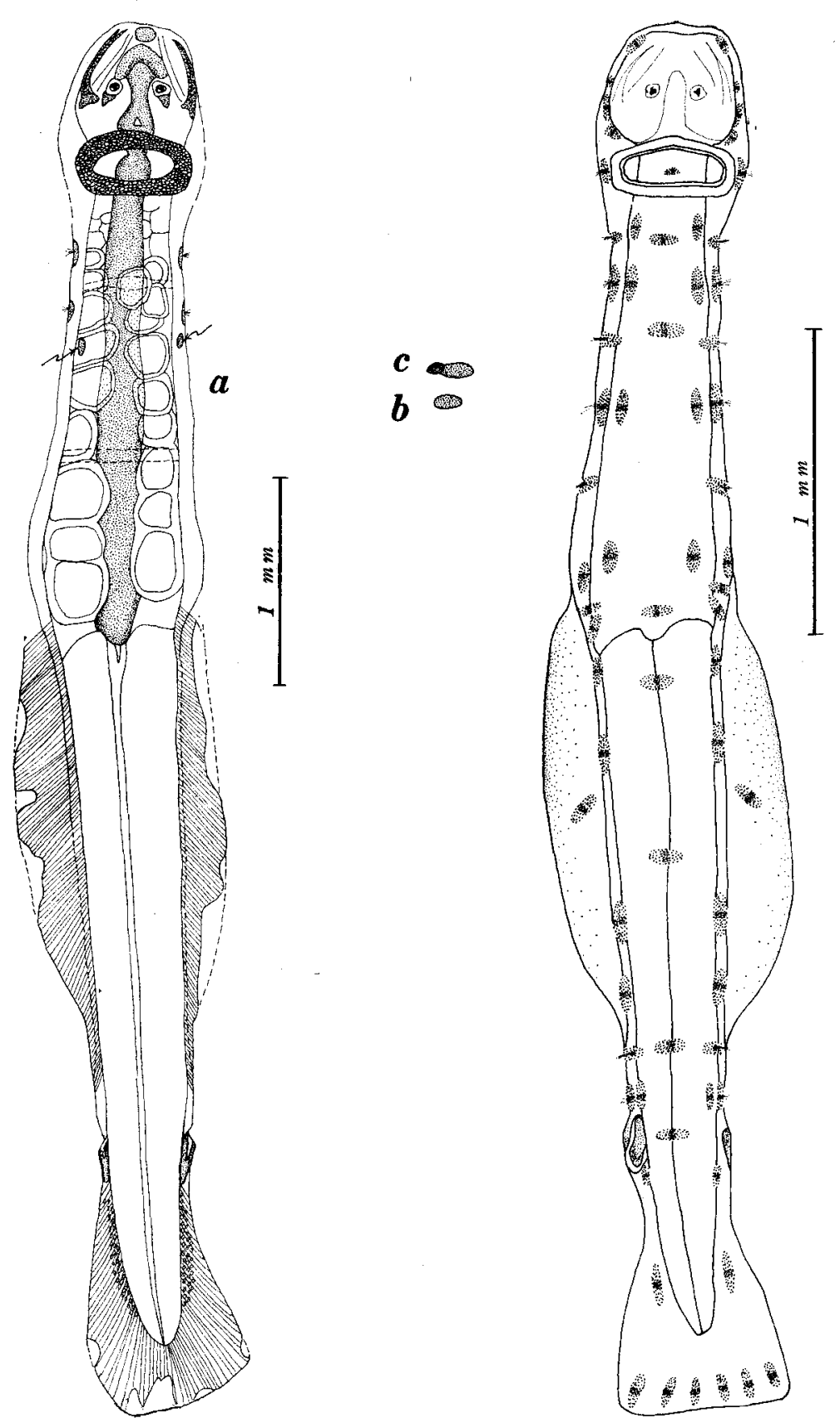

Fig. 1a. Type specimen of Spadella bradshawi, unstained. Arrows indicate the lateral orange-brown spots. $1 \mathrm{~b}$, side view of the orange-brown spot of the type. $1 \mathrm{c}$, orange-brown spot of the paratype from side view. Dashed lines across the trunk indicate orange-brown stripes on the ventral side.

Fig. 2. Sensory spots of Spadella bradshawi stained with aniline blue (WS). Composite of several specimens. Small papillate protuberances shown as dots cover the outer edges of the lateral fins. 


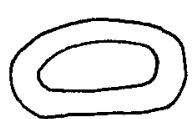

$\boldsymbol{a}$

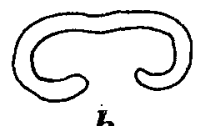

$\boldsymbol{b}$

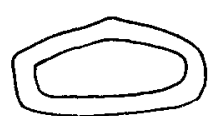

c

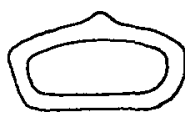

$\boldsymbol{d}$

Fig. 3. Outlines of stained coronas. 3a, type specimen twenty-four hours after preservation. 3b, broken corona of the paratype. $3 c$, corona of the type specimen two months after preservation. $3 \mathrm{~d}$, corona of a specimen preserved in dilute formalin for nineteen years.

(1939) show three forms much like those of Fig. 3 for Spadella cephaloptera. Kado and " Hirota (1957) report a change in the shape of the corona of Aidanosagitta crassa and correlate it to the body length, water temperature and season. Ghiradelli (1968) illustrates several shapes of corona in Flaccisagitta enflata and Zonosagitta pulchra. Owre (1963) speculated that the corona might change with age of the individual. Apparently the change in the shape of the corona with preservation has not been reported in the literature. These observations cast some doubt on the utility of the corona in taxonomic discrimination in Spadella.

The number of hooks on one jaw, counted on twelve specimens, ranged from seven to twelve with a mean of 10.3. The anterior teeth on one side ranged from three to six with a mean of 4.4. I observed no posterior teeth. Chaetognaths shrink after preservation in formalin and the length as well as body proportions continue to change for many years (Ahlstrom and Thrailkill, 1963; Owre, 1963; Bieri, unpublished). Therefore only the length and tail segment per cent of the freshly killed type and paratype are given below.

\begin{tabular}{lccrc} 
Specimen & $\begin{array}{c}\text { Total Length } \\
\mathrm{mm}\end{array}$ & $\begin{array}{c}\text { Tail segment as } \% \\
\text { of Total Length }\end{array}$ & Hooks & Ant. Teeth \\
Type & 6.5 & 54 & $8-9$ & $4-5$ \\
Paratype & 5.5 & 53 & $7-8$ & $4-5$ \\
\multicolumn{2}{r}{ Old Specimens, Mean Length $4.9 \mathrm{~mm}$, Range: $4.4-5.3 \mathrm{~mm}$} & Ant. Teeth \\
Hooks & Ant. Teeth & Hooks & $5-4$ \\
$11-11$ & $5-5$ & $11-11$ & $3-3$ \\
$10-11$ & $5-5$ & $11-11$ & $5-4$ \\
$11-12$ & $5-6$ & $10-10$ & $4-5$ \\
$11-11$ & $4-5$ & $10-10$ & $5-5$ \\
$11-11$ & $4-4$ & $10-11$ &
\end{tabular}

The lateral fins are rayed throughout. They extend anteriorly beyond the transverse septum but do not reach the seminal vesicles.

The ventral ganglion covers the middle third of the trunk segment.

The ovaries extend almost to the neck. The eggs mature at different times and are so large when mature that they cause a swelling in the body just anterior to the transverse septum.

The seminal vesicle begins at the anterior end of the tail fin but does not reach the posterior end of the lateral fin. As it approaches maturity the vesicle develops a tube which projects anteriorly from the side of the vesicle (Fig. 4). 
The color of the tail segment in freshly killed specimens is milky-white. There are two conspicuous orange-brown spots on either side of the trunk half way between the head and the transverse septum (Fig. 1a). In side view they are oval in the type specimen and dumbell-shaped in the paratype (Fig. 1b, 1c). Two orange-brown stripes cross the trunk on the ventral side, one anterior and one posterior to the lateral spots (Fig. 1a, dashed lines across the trunk). The gut from the transverse septum to the middle of the largest pair of eggs is orangebrown and is surrounded by an area with a greenish tinge. The seminal vesicles have an orange-brown tinge. In reflected light the eyes are shiny green-black.
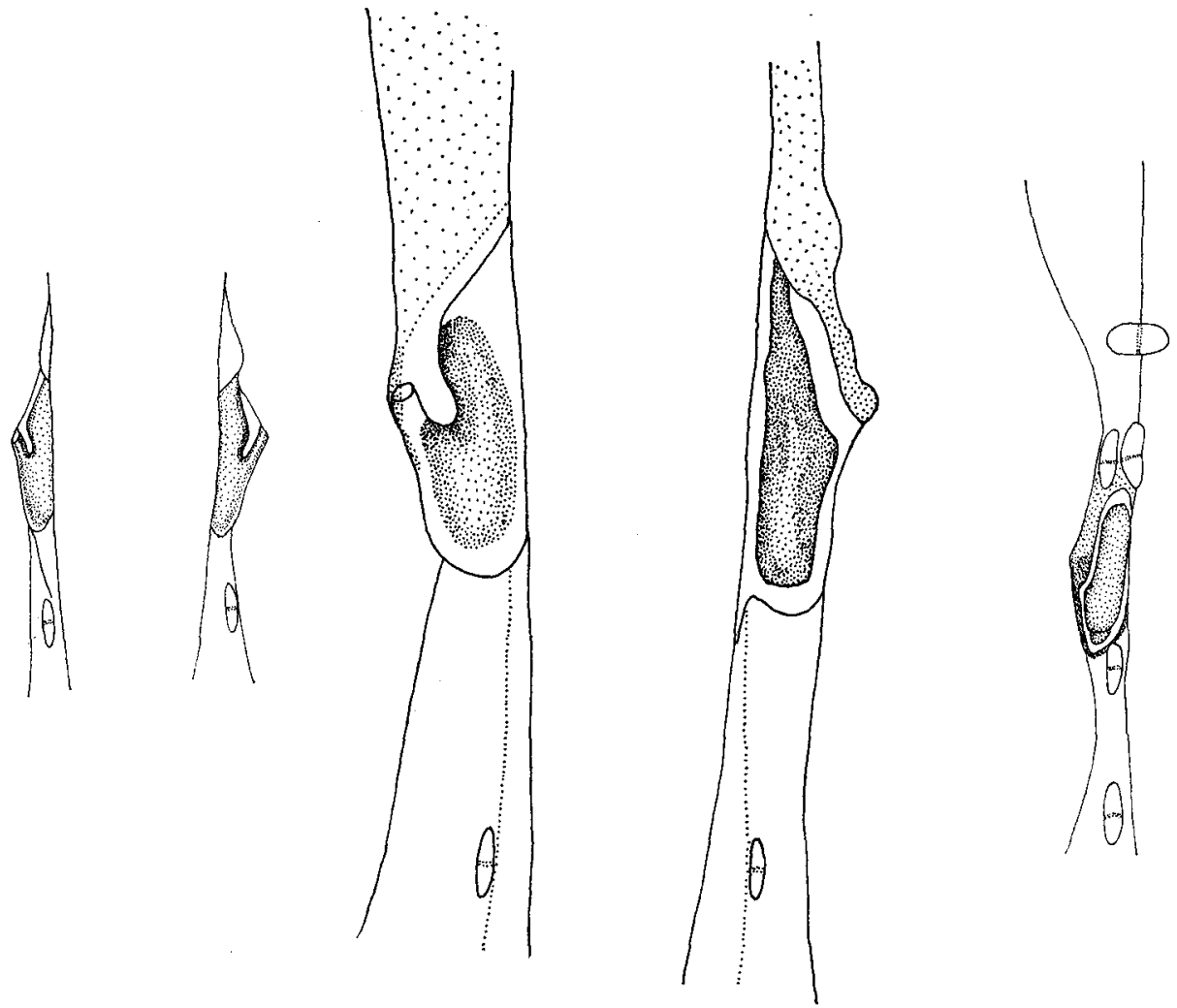

Fig. 4. Seminal vesicles in various stages of development.

Spadella bradshawi belongs to the group formed by Sp. cephaloptera and Sp. angulata because it lacks the adhesive organs characteristic of the $S p$. schizoptera group (Yosii and Tokioka, 1939; Mawson, 1944; Owre, 1963 and 1972; Tokioka and Pathansali, 1964; Alvariño, 1970). The lateral fins of Sp. bradshawi as in Sp. angulata extend anterior to the transverse septum. Thus it can be distinguished from Sp. cephaloptera. It is a kind of California "twin" to Sp. angulata. In the list below I summarize the differences between the two. 
Spadella angulata

1. Ovary extends about half the length of the trunk.

2. Intestinal diverticulum present.

3. Seminal vesicle reaches the lateral fin.

4. Color pattern -has five orange-brown rings on the dorsal side of the tail segment. Has no stripes on the ventral side of the trunk.

5. The seminal vesicle has an angular shape when mature or a bulb near the tail fin when maturing.

6. The sensory tufts on the midline of the dorsal side of the tail segment are five in number and are about evenly spaced along the tail segment.
Spadella bradshawi

Ovary extends almost to the neck.

Intestinal diverticulum absent.

Seminal vesicle does not reach the lateral fin. Has no orange-brown rings on the tail segment. Has two transverse orange-brown stripes on the ventral side of the trunk. The seminal vesicle is " $U$ " shaped with a small tube projecting anteriorly from near the middle of the seminal vesicle to about twothirds the length of the seminal vesicle. In a fully mature vesicle this might become angular. The sensory tufts on the mid-line of the dorsal side of the tail segment are four in number. Two are close together near the seminal vesicle, the two anterior ones are further apart.

7. The hook and tooth formulas are very similar but:

Has zero to one posterior teeth.

Has no posterior teeth.

Hooks 8-9

Hooks 7-11

Anterior teeth 2-4

Anterior teeth 3-6

8. Maximum Body Length Reported $5.8 \mathrm{~mm}$

$6.5 \mathrm{~mm}$

9. The tail segment per cent overlaps 48.6-57.9

$53-54$

It is a great pleasure to name this beautiful animal, the first species of Spadella reported from the Eastern Pacific, after my very good friend and colleague, Dr. J. S. Bradshaw. The types are deposited in the U.S. National Museum, holotype USNM 45540, paratype USNM 45541. Both were collected off San Diego at 117-21 W. Long., 32-39 N. Lat. in 140 meters of water on July 27, 1971 at 1155 to 1210 Pacific Daylight Time.

\section{Ecological Notes}

Spadella bradshawi has been trawled from depths of 25 to 150 meters but has not been taken in a series of shallower tows nor in deeper tows. The greatest number of specimens were taken at 60 meters. In July, 1952, it was taken at 40 to 50 meters when the bottom temperature was $10.9^{\circ} \mathrm{C}$. It was not taken in the Zostera beds. It appears to be most abundant over relatively coarse sand but is also found on sediments with a high percentage of silt. Of the nine species of Spadella listed by Alvariño (1970) only $S p$. sheardi from 100 meters, Sp. johnstoni from 70 meters and $S p$. angulata from 50 meters have been taken from depths approaching this. It may be that further north, where the temperatures are lower, Sp. bradshawi occurs in shallower water. Up to this time however, the species has only been taken off San Diego due west of Point Loma and south to the Coronado Islands. 
The species appears to reproduce throughout the year. It is often taken with a variety of orange-colored animals including arenaceous foraminifera, harpacticoid copepods, ostracods and cumaceans. In some areas there is coarse orange sand in the substrate of the community. Although as many as 240 specimens were taken in a single trawl, they are rather sparsely distributed and probably average less than one individual in a square meter of sea floor.

\section{Acknowledgments}

I wish to thank Takasi Tokioka for valuable advice and criticism. J.S. Bradshaw has supported my work on the epibenthos for many years with equipment, boats and hard labor. A variety of organizations inadvertently supported this research-to them also my thanks.

\section{REFERENCES}

Ahlstrom, E.H. and J.R. Thrailkill 1963. Plankton volume loss with time of preservation. CalCOFI Repts., 9, 57-73.

Alvarino, A. 1970. A new species of Spadella (benthic Ghaetognatha). Studies Fauna Curaçao Caribbean Isls., 34, 73-89.

Ghirardelli, E. 1968. Some aspects of the biology of the chaetognaths. Adv. Mar. Biol., 6, 271-375.

Kado, Y. and R. Hirota 1957. Further studies on the seasonal variation of Sagitta crassa. J. Sci. Hiroshima Univ., Ser. B, Div. 1 (Zool.), 17, 131-136.

Mawson, P.M. 1944. Some species of the chaetognath genus Spadella from New South Wales. Trans. Roy. Soc. South Australia, 68, 327-333.

Owre, H.B. 1963. The genus Spadella (Chaetognatha) in the western North Atlantic Ocean, with descriptions of two new species. Bull. Mar. Sci. Gulf and Carib., 13, 378-390.

- 1972. Marine Biol. Invest. Bahamas 18. The genus Spadella and other Chaetognatha. Sarsia, 49, 49-58.

Tokioka, T. and D. Pathansali 1964. Spadella cephaloptera forma angulata raised to the rank of species. Publ. Seto Mar. Biol. Lab., 12, 145-148.

Tokioka, T. and R. Bieri 1966. The colour pattern of Spadella angulata Tokioka. Publ. Seto Mar. Biol. Lab., 14, 323-326.

Yosii, N. and T. Tokioka 1939. Notes on Japanese Spadella (Chaetognatha). Annot. Zool. Japon., $18,267-273$. 